\title{
Research and Progress of Transparent, Flexible Tin Oxide Ultraviolet Photodetector
}

\author{
Qiannan Ye ${ }^{1}$, Xu Zhang ${ }^{1}$, Rihui Yao ${ }^{1, *} \mathbb{C}$, Dongxiang Luo ${ }^{2} \mathbb{D}$, Xianzhe Liu $^{3}$, Wenxin Zou ${ }^{1}$, Chenxiao Guo ${ }^{1}$, \\ Zhuohui $\mathrm{Xu}^{4, *}$, Honglong Ning ${ }^{1}{ }^{1}$ and Junbiao Peng ${ }^{1}$
}

1 Institute of Polymer Optoelectronic Materials and Devices, State Key Laboratory of Luminescent Materials and Devices, South China University of Technology, Guangzhou 510640, China; msyeqiannan@mail.scut.edu.cn (Q.Y.); 201921020680@mail.scut.edu.cn (X.Z.);

201830640491@mail.scut.edu.cn (W.Z.); mschenxiaoguo@mail.scut.edu.cn (C.G.); ninghl@scut.edu.cn (H.N.); psjbpeng@scut.edu.cn (J.P.)

2 Institute of Clean Energy and Materials, Guangzhou Key Laboratory for Clean Energy and Materials, Huangpu Hydrogen Innovation Center, School of Chemistry and Chemical Engineering, Guangzhou University, Guangzhou 510006, China; luodx@gdut.edu.cn

3 Research Center of Flexible Sensing Materials and Devices, School of Applied Physics and Materials, Wuyi University, Jiangmen 529020, China; msliuxianzhe@mail.scut.edu.cn

4 Guangxi Key Lab of Agricultural Resources Chemistry and Biotechnology, Yulin Normal University, Yulin 537000, China

* Correspondence: yaorihui@scut.edu.cn (R.Y.); xzh21@ylu.edu.cn (Z.X.)

Citation: Ye, Q.; Zhang, X.; Yao, R.; Luo, D.; Liu, X.; Zou, W.; Guo, C.; Xu, Z.; Ning, H.; Peng, J. Research and Progress of Transparent, Flexible Tin Oxide Ultraviolet Photodetector. Crystals 2021, 11, 1479. https:// doi.org/10.3390/cryst11121479

Academic Editors: Julien Brault and Ching-Hwa Ho

Received: 7 November 2021

Accepted: 25 November 2021

Published: 28 November 2021

Publisher's Note: MDPI stays neutral with regard to jurisdictional claims in published maps and institutional affiliations.

Copyright: (c) 2021 by the authors. Licensee MDPI, Basel, Switzerland. This article is an open access article distributed under the terms and conditions of the Creative Commons Attribution (CC BY) license (https:// creativecommons.org/licenses/by/ $4.0 /)$.

\begin{abstract}
Optical detection is of great significance in various fields such as industry, military, and medical treatment, especially ultraviolet (UV) photodetectors. Moreover, as the demand for wearable devices continues to increase, the UV photodetector, which is one of the most important sensors, has put forward higher requirements for bending resistance, durability, and transparency. Tin oxide $\left(\mathrm{SnO}_{2}\right)$ has a wide band gap, high ultraviolet exciton gain, etc., and is considered to be an ideal material for preparing UV photodetectors. At present, $\mathrm{SnO}_{2}$-based UV photodetectors have a transparency of more than $70 \%$ in the visible light region and also have excellent flexibility of $160 \%$ tensile strain. Focusing on $\mathrm{SnO}_{2}$ nanostructures, the article mainly summarizes the progress of $\mathrm{SnO}_{2}$ UV photodetectors in flexibility and transparency in recent years and proposes feasible optimization directions and difficulties.
\end{abstract}

Keywords: UV photodetector; $\mathrm{SnO}_{2}$; transparent; flexible; wearable

\section{Introduction}

As one of the most important optoelectronic devices, UV photodetectors are hugely in demand in space communications, missile warning, ozone layer monitoring, flame detection, and spectral analysis in the medical field [1-6]. Compared with traditional UV photodetectors, which have low single detection quality in complex application environments due to rigid obstacles, flexible detectors can collect information more effectively and produce higher quality signals [7]. Particularly, transparent and flexible UV photodetectors play an important role in the progress of wearable photodetection. Most UV photodetectors convert photons into carriers, causing the circuit to produce voltage or current changes, thereby converting the detected light signals into electrical signals.

As for photosensitive materials, they can be roughly divided into organic and inorganic materials. Though printable and solution-processed organic semiconductors are widely used in UV photodetectors [8], improving the life of the device has always been a problem. Among the inorganic materials, silicon, as one of the traditional materials for preparing photodetectors, has limited absorption range and weak absorption, and silicon photodetectors need to use expensive filters to resist interference, which increases equipment costs. In addition, the filter may cause visible light leakage after long-term use, 
thereby reducing the service life of the device. In recent years, due to the advantages of high electron saturation drift speed, high thermal conductivity, and high breakdown strength, wide-band gap semiconductors, including group III nitrides (such as $\mathrm{GaN}$, etc.), $\mathrm{SiC}$, metal oxides (such as $\mathrm{TiO}_{2}, \mathrm{ZnO}, \mathrm{SnO}_{2}$, etc.), and so on, have broad application prospects in UV photodetectors $[9,10]$. Among the above semiconductors, III-nitrides and $\mathrm{SiC}$ are expensive, inflexible, and difficult to prepare in a large area, while metal oxides have attracted a wide range of researchers' interest due to their easy preparation, flexibility, transparency, and printability [11,12]. Table 1 summarizes the development of UV photodetectors of different materials in recent years.

Table 1. The parameters of UV photodetector prepared by different materials.

\begin{tabular}{|c|c|c|c|c|c|c|c|}
\hline Structure & Material & Bias (V) & $\begin{array}{c}\text { Dark } \\
\text { Current }\end{array}$ & $\begin{array}{l}\text { Detectivity } \\
\text { (Jones) }\end{array}$ & $\begin{array}{l}\text { Responsivity } \\
\text { (A/W) }\end{array}$ & Response Time (s) & Ref. \\
\hline $\mathrm{p}-\mathrm{i}-\mathrm{n}$ & $\mathrm{SiC} / \mathrm{Si}$ & - & $10^{-11} \mathrm{~A} / \mathrm{cm}^{2}$ & - & 0.28 & - & [13] \\
\hline$p-i-n$ & $4 \mathrm{H}-\mathrm{SiC}$ & 5 & $2.5 \mathrm{pA} / \mathrm{mm}^{2}$ & - & 0.13 & - & {$[14]$} \\
\hline MSM & $\mathrm{Cs}_{2} \mathrm{AgInCl}_{6}$ & 5 & $10 \mathrm{pA}$ & $\sim 10^{12}$ & $\sim 0.013$ & $0.8 \mathrm{~ms} / 1 \mathrm{~ms}$ & [15] \\
\hline MSM & $(\mathrm{PEA})_{2} \mathrm{PbBr}_{4}$ & 10 & $\sim 0.25 \mathrm{pA}$ & $1.55 \times 10^{13}$ & $\sim 0.031$ & $0.41 \mathrm{~ms} / 0.37 \mathrm{~ms}$ & [16] \\
\hline MSM & $\mathrm{ZnO}$ & $2 \times 10^{-4}$ & $1.32 \mathrm{pA}$ & $1.45 \times 10^{15}$ & 0.014 & $250 \mathrm{~s} / 150 \mathrm{~s}$ & [17] \\
\hline pn junction & $\mathrm{ZnO}-\mathrm{Ga}_{2} \mathrm{O}_{3}$ & 0 & $\sim 1 \mathrm{nA}$ & $6.29 \times 10^{12}$ & $9.7 \times 10^{-3}$ & $0.1 \mathrm{~ns} / 0.9 \mathrm{~ns}$ & [18] \\
\hline 3D nano- herojunction & $\mathrm{NiO} / \mathrm{ZnO}$ & 1 & $18 \mathrm{pA}$ & - & 13 & $5 \mathrm{~s} / 9 \mathrm{~s}$ & [19] \\
\hline pn junction & $\mathrm{GaN} / \mathrm{Ga}_{2} \mathrm{O}_{3}$ & 0 & - & $1.23 \times 10^{11}$ & $5.443 \times 10^{-3}$ & $0.1 \mathrm{~s} / 0.08 \mathrm{~s}$ & [20] \\
\hline herojunction & $\mathrm{SnO}_{2} / \mathrm{GO}$ & 1 & $100 \mathrm{nA}$ & $1.4 \times 10^{15}$ & 395 & $120 \mathrm{~s} / 100 \mathrm{~s}$ & [21] \\
\hline herojunction & $\mathrm{ZnO} / \mathrm{GO}$ & 1 & $0.18 \mu \mathrm{A}$ & $2.6 \times 10^{12}$ & $\sim 0.3$ & $160 \mathrm{~s} / 190 \mathrm{~s}$ & [22] \\
\hline HEMTstack & InAlN/GaN & 5 & $<32 \mathrm{pA}$ & - & 32.9 & $3.6 \mathrm{~ms} / 4.2 \mathrm{~ms}$ & [23] \\
\hline FET & ZnO NRs & 5 & - & - & $2.5 \times 10^{6}$ & - & [24] \\
\hline
\end{tabular}

Among the most popular metal oxide semiconductors used in optoelectronic devices, $\mathrm{SnO}_{2}$ is considered to be one of the most favorable candidate semiconductors [25]. Intrinsic $\mathrm{SnO}_{2}$ has a wide band gap at room temperature, is transparent in the visible light region, has a wide range of uses, can be flexible, and has an exciton binding energy of $130 \mathrm{meV}$, stable and corrosion-resistant, making it an ideal material for preparing UV photodetectors [26]. The existence of defects and dangling bonds in $\mathrm{SnO}_{2}$ plays an important role in the process of light transmission and light detection [27]. Recent studies have shown that the use of surface defect states to capture weak bounded excitons can generate large ultraviolet exciton gains in $\mathrm{SnO}_{2}$ nanostructures through the giant oscillator strength effect, and due to the large surface area to volume ratio of $\mathrm{SnO}_{2}$ nanostructures, the number of surface defects has increased significantly $[28,29]$. These factors make it possible to prepare high-gain $\mathrm{SnO}_{2}$ nanostructured UV photodetectors. A UV photodetector with high photocurrent gain based on $\mathrm{SnO}_{2}$ nanowires was reported by $\mathrm{Lin}$ et al, with a gain of up to 8000 [30]. Additionally, it is reported that devices based on graphene oxide (GO) and $\mathrm{SnO}_{2}$ nano-heterogeneous devices have an ultra-high response rate (395 A/W) and excellent $\mathrm{I}_{\text {Photo }} / \mathrm{I}_{\text {Dark }}$ value (2380) in ultraviolet light $(312 \mathrm{~nm}$ ) [21]. In contrast, the performance of UV photodetectors made of $\mathrm{SnO}_{2}$ thin film is relatively poor [31,32].

According to the dimensionality, $\mathrm{SnO}_{2}$ materials can be divided into one-dimensional, two-dimensional, and three-dimensional. Among them, one-dimensional nanostructures include nanowires (NWs), nanotubes (NTs), nanobelts (NBs), nanorods (NRs), etc.; twodimensional structures include nanosheets (NSs), etc.; three-dimensional structures include thin films, microwires (MWs) and so on. Currently, various $\mathrm{SnO}_{2}$ nanostructures, such as nanowires [33], nanowire arrays [34], nanobelts [35], etc., have been prepared and applied to photodetectors. In view of the slow response speed and poor detectivity faced by $\mathrm{SnO}_{2}$ UV photodetectors, various $\mathrm{SnO}_{2} \mathrm{UV}$ photodetectors with different device structures have been prepared and constructed to achieve different performance optimizations.

This review mainly focuses on $\mathrm{UV}$ photodetectors based on $\mathrm{SnO}_{2}$, starting from the basic parameters and structures of the photodetectors, and then discussing the progress of transparent, flexible UV photodetectors in recent years. Finally, the optimization of the performance of $\mathrm{SnO}_{2} \mathrm{UV}$ photodetectors is discussed. 


\section{The Parameters and Structures of Photodetectors}

\subsection{Parameters}

\subsubsection{Dark Current}

Dark current refers to the current that exists in the photodetector when there is no incident light. A good photodetector has a large ratio of photocurrent to dark current. Generally, dark current is generated by the following situations [36]: (1) When an ohmic contact is formed between the electrode and the semiconductor layer, there is a potential difference between the electrode and the semiconductor layer, and electrons and holes will move to the positive electrode and the negative electrode, respectively, to form a current; (2) When the metal and the semiconductor are in contact, due to the tunneling effect, the carrier may pass through the barrier and form a current; (3) If the semiconductor is non-uniformly doped, carriers will diffuse from the high-concentration area to the low-concentration area, and so on.

\subsubsection{Responsivity}

The responsivity $(\mathrm{R})$ refers to the ratio of the photocurrent generated by the device to the incident light power under the excitation of a specific wavelength, and it is also proportional to the external quantum efficiency (EQE), which can be expressed by the formula (1). The responsivity spectrum can be obtained by measuring the photocurrent of the photodetector in a specific spectral range under illumination.

$$
\mathrm{R}=\frac{\mathrm{I}_{\mathrm{ph}}-\mathrm{I}_{\mathrm{dark}}}{\mathrm{P}_{\text {light }}}=\frac{\mathrm{EQE}}{\mathrm{hc} / \mathrm{e} \lambda}
$$

where $I_{p h}$ is the photocurrent generated by the device, $I_{\text {dark }}$ is the dark current of the device, plight is the power of the incident light, $h, c, e, \lambda$ are Planck's constant, speed of light, electron charge, and incident wavelength, respectively, and EQE is the external quantum efficiency. The responsivity is usually related to the device structure, material, etc. For example, the gain of an avalanche photodiode will produce a higher responsivity. The external quantum efficiency refers to the ratio of the number of electron-hole pairs collected to the number of incident photons per second. Generally, a photon can only excite a pair of electron-hole pairs, so the EQE will be less than 100\%. However, in a special photodetector, when the exciton energy is greater than the band gap value, a photon can excite several electron-hole pairs, and the EQE will be greater than $100 \%[37,38]$.

\subsubsection{Detectivity}

Specific detectivity $\left(D^{*}\right)$ represents the smallest optical signal that the device can detect, which is related to the responsivity and noise of the device, and can be expressed by formula (2):

$$
\mathrm{D}^{*}=\frac{\mathrm{R} \sqrt{\mathrm{AB}}}{\mathrm{i}_{\text {noise }}},
$$

where $\mathrm{R}$ is the responsivity, $\mathrm{A}$ is the effective area under illumination, $\mathrm{B}$ is the detection bandwidth, and $i_{\text {noise }}$ is the total noise measured.

\subsubsection{Response Time}

Response time is another criterion for evaluating the quality of photodetectors. Response time refers to the time required for the output of the detector to respond to changes in the input light intensity, and it consists of two parts: rise time and decay time. In the case of pulses, the rise time refers to the time required for the photodetector output level to change from $10 \%$ to $90 \%$ of the peak output level, and the decay time refers to the time required for the output level to change from $90 \%$ of the peak output level to $10 \%$. The 
light response curve of a typical photodetector can be fitted using the double exponential relaxation equation (Equation (3)).

$$
\mathrm{I}=\mathrm{I}_{0}+\mathrm{C}_{1} \mathrm{e}^{-\mathrm{t} / \tau_{1}}+\mathrm{C}_{2} \mathrm{e}^{-\mathrm{t} / \tau_{2}},
$$

where $\mathrm{I}_{0}$ is the steady-state current, $\mathrm{C}_{1}$ and $\mathrm{C}_{2}$ are constants, $\tau_{1}$ and $\tau_{2}$ are the relaxation time constants, and $\mathrm{t}$ is the time.

\subsubsection{Gain}

Gain is another important parameter of photodetectors. Due to the applied bias, the light in the material excites the holes to migrate to the anode, but the electrons are trapped by the defects. Once the holes reach the anode, due to the conservation of charge in the material, the holes will be replenished from the cathode at this time. This process will continue until the holes recombine with the trapped electrons. Therefore, after a single electron-hole photogeneration, multiple holes circulate in the material, resulting in high gain [39]. The gain can be calculated from the measured carrier lifetime and transit time, as shown in Equation (4) [40].

$$
\text { Gain }=\frac{\tau_{\text {lifetime }}}{\tau_{\text {transit }}}=\frac{\tau_{\text {lifetime }}}{\mathrm{d}^{2} / \mu \mathrm{V}},
$$

where $\tau_{\text {lifetime }}$ is the carrier lifetime, $\tau_{\text {transit }}$ is the transport time of carriers between electrodes, $\mathrm{d}$ is the thickness of the device, $\mu$ is carrier mobility, and $\mathrm{V}$ is the bias voltage. Compared with EQE, the gain can reach a large value. When the distance between the electrodes is less than the mean free path of carriers, the gain is always greater than 1 . High gain means high sensitivity, making the detector suitable for applications such as fiber optic communication receivers, high-resolution imaging, and laser microscopes [41].

\subsection{Device Structures}

According to the different working mechanism, the device structure of a UV photodetector can be divided into the photoconductive type and photovoltaic type.

The photoconductive UV photodetector is generally composed of electrodes and lightsensitive $\mathrm{SnO}_{2}$, as shown in Figure 1a. When light is irradiated, the carrier concentration of $\mathrm{SnO}_{2}$ in the device will change, which will cause a change in conductivity, and this change will eventually be the output in the form of current. This kind of device structure is easy to prepare and has a low cost, and they usually have a higher gain, but longer response time [42,43], and they also have higher dark current and noise. On the surface of $\mathrm{SnO}_{2}$ which is generally not modified by other materials, due to the periodic break of the crystal lattice, a large number of dangling bonds are formed, and the surface state of the acceptor type is generated on the surface. Electrons are transferred from the inside to the surface, causing a carrier depletion layer to form near the surface and causing the band to bend. Therefore, the surface will dominate the photocurrent transport in the one-dimensional nanostructure [44,45].

The photovoltaic UV photodetector separates the photogenerated electron-hole pairs by establishing a built-in electric field. The electrons and holes are collected by the cathode and the anode, respectively, which causes the voltage change of the external circuit to achieve the purpose of converting optical signals into electrical signals. As shown in Figure $1 \mathrm{~b}$, the built-in electric field can be generated through the contact between $\mathrm{n}$-type and p-type materials. Of course, when the contact between the metal electrode and the n-type $\mathrm{SnO}_{2}$ material is Schottky contact, the energy band of the $\mathrm{SnO}_{2}$ semiconductor at the interface will be bent, forming a Schottky barrier, achieving the effect of separating electron-hole pairs [46]. In addition, because the preparation of good p-type materials is relatively difficult, the built-in electric field can also be generated by using two materials with different working functions. This situation is similar to Schottky contact, as shown in Figure 1c. 


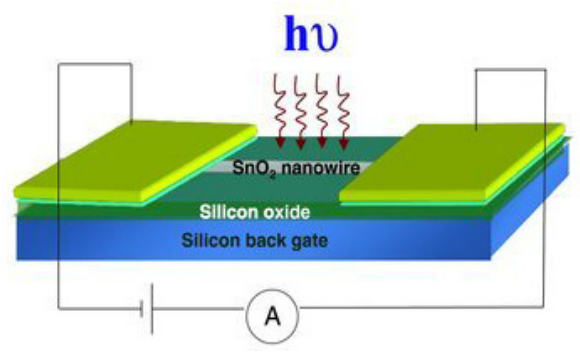

(a)

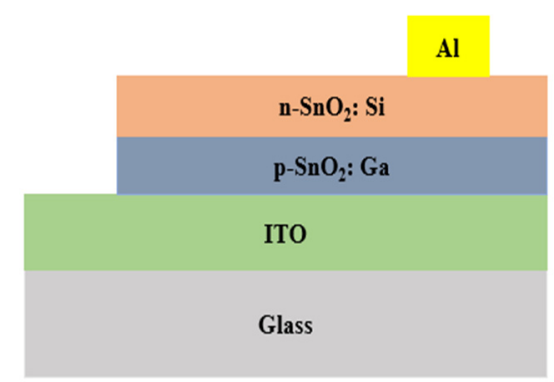

(b)

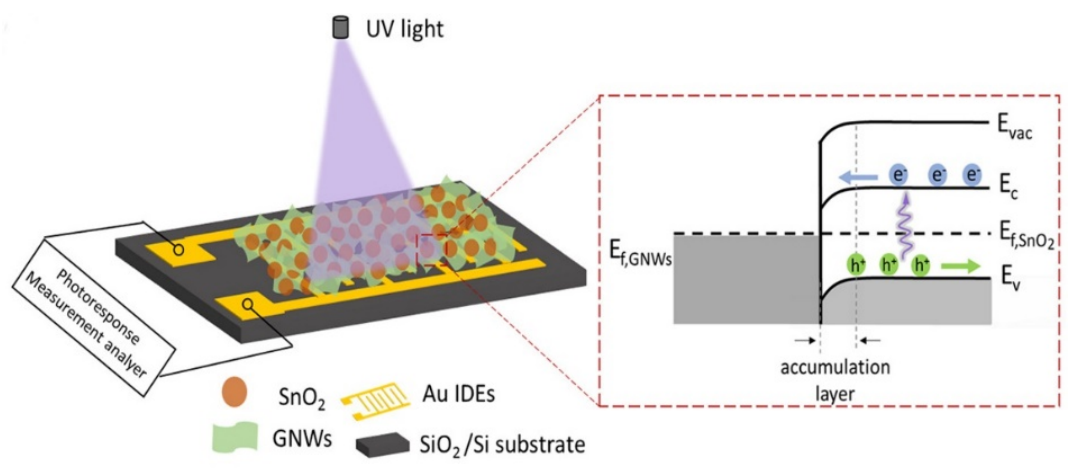

(c)

Figure 1. (a) $\mathrm{SnO}_{2}$ nanowire UV detector structure diagram. Reproduced with permission from Ref. [47]; 2011, Wiley; (b) Schematic representation of $\mathrm{Al} / \mathrm{SnO}_{2}: \mathrm{Si} / \mathrm{SnO}_{2}: \mathrm{Ga} / \mathrm{ITO}$ heterojunction photodiode [21]; (c) Structure diagram and working mechanism of $\mathrm{GNWs} / \mathrm{SnO}_{2}$ devices under UV light. Reproduced with permission from Ref. [48]; 2019, Elsevier.

\section{Transparent $\mathrm{SnO}_{2}$ UV Photodetector}

The optical band gap width of $\mathrm{SnO}_{2}$ at room temperature is $3.6 \sim 4.3 \mathrm{eV}$. When the energy of photons incident on the $\mathrm{SnO}_{2}$ material is less than the optical band gap width, most of the photons will pass through. At this time, the $\mathrm{SnO}_{2}$ material will show good transparency in this waveband. The photon energy value of visible light is $3.1 \mathrm{eV}$, so $\mathrm{SnO}_{2}$ material has good transparency in the visible light range $(380 \sim 780 \mathrm{~nm})$. If matched with other suitable functional layers and substrates, it is possible to realize a transparent UV photodetector.

Among many metal oxides, zinc oxide $(\mathrm{ZnO})$, nickel oxide $(\mathrm{NiO})$ and so on, which have band gaps of $3.3 \mathrm{eV}, 3.5 \mathrm{eV}$, etc., have good transparency in visible light range and are often used in UV photodetectors when combined with $\mathrm{SnO}_{2}$. Based on the electrospinning technology, Tian and his team reported a $\mathrm{ZnO} / \mathrm{SnO}_{2}$ nanofiber UV photodetector with a transparency of up to $90 \%$ in the visible light band [49], as shown in Figure $2 a$. Figure $2 b$ shows the spectral response of the photodetector to different wavelengths and the strong absorption at wavelengths below $350 \mathrm{~nm}$ in the light absorption spectrum; for light with a wavelength of more than $400 \mathrm{~nm}$, the responsivity is very low. Although the device has good transparency, the response time is longer, and the rise and decay times are $32.2 \mathrm{~s}$ and $7.8 \mathrm{~s}$, respectively, which is similar to the $\mathrm{p}-\mathrm{SnO}_{2}: \mathrm{Ga} / \mathrm{n}-\mathrm{Ga}_{2} \mathrm{O}_{3}$ nanowire $\mathrm{UV}$ photodetector reported by Hsu [50]. This may be since a large number of photogenerated carriers are trapped by defects in the metal oxide and the distance between the electrodes is smaller than the mean free path of the photogenerated carriers, and thus the gain and the response speed are reduced.

The connection structure of the nanostructure heterojunction usually includes: overlapping n-type $\mathrm{SnO}_{2}$ and p-type material films, crossed n-type and p-type nanofibers, and so on. Compared with the $\mathrm{n}-\mathrm{SnO}_{2}$ nanobelt/p-NiO thin film UV photodetector re- 
ported [51] by Long et al., the n-SnO 2 -p-NiO nanofiber array (NFA) UV photodetector has a cross-bar structure prepared by the electrospinning method, and the transmittance of the device can reach $\sim 90 \%$ in the visible light region, which is mainly due to the pores of the $\mathrm{SnO}_{2}-\mathrm{NiO}$ fiber cross-bar structure and the wide band gap of the semiconductor [52]. Under $-5 \mathrm{~V}$ bias, the highest responsivity of the device occurs at $250 \mathrm{~nm}$, which is close to $\sim 8.67 \mathrm{~A} / \mathrm{W}$, and the EQE is calculated to be $4337.17 \%$. The authors believe that this is due to the trap states in $\mathrm{p}-\mathrm{NiO}$ trapping photo-generated holes and also because the electron mobility in $\mathrm{n}-\mathrm{SnO}_{2}$ is relatively high, so the electrons will circulate in the circuit many times and realize the optical gain effect [53]. The photodetector can also work at $0 \mathrm{~V}$, the photocurrent is $10^{-10} \mathrm{~A}$, and the on-off ratio is about 140 , which is expected to be used in automatic force detectors.

Due to the existence of surface states such as surface electron traps and oxygen adsorption, $\mathrm{SnO}_{2} \mathrm{UV}$ photodetectors generally have good sensitivity, but they also limit the further improvement of response speed. This is because these defects act as a recombination center, which traps photo-generated carriers and reduces the efficiency of light detection. At the same time, they are like donor impurities, leading to a huge carrier concentration $[54,55]$, and therefore the photodetectors have a large dark current, hindering the optimization of the response time and photocurrent of the device. The construction of the core-shell structure can modify the surface of $\mathrm{SnO}_{2}$ and reduce oxygen adsorption and can also construct a heterojunction, generate a built-in electric field to promote the separation of photogenerated electron-hole pairs, and effectively improve the performance of the device.

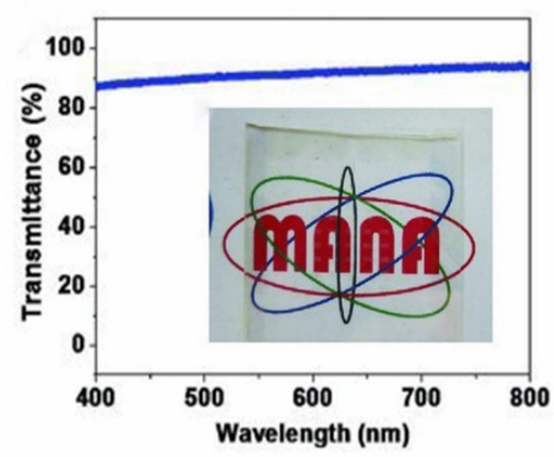

(a)

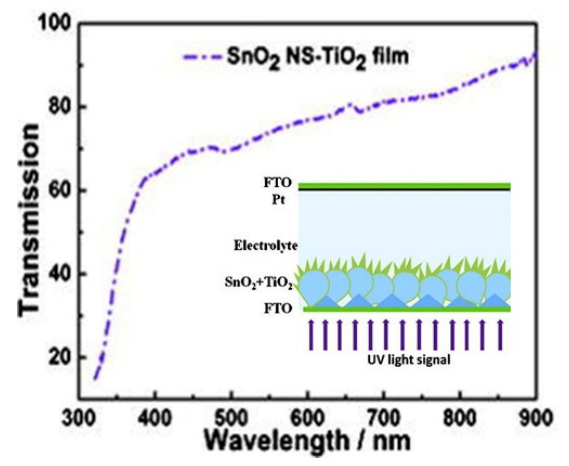

(c)

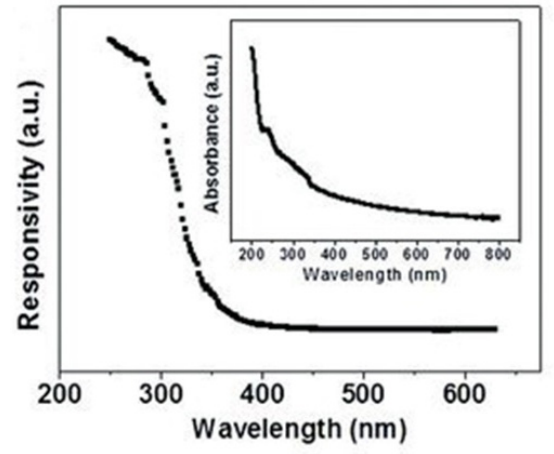

(b)

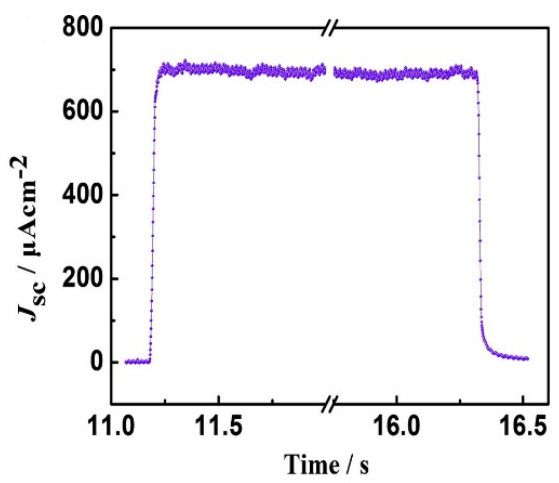

(d)

Figure 2. (a) Optical transmittance of the device in glass; (b) Spectroscopic photoresponse of the device measured at a bias of $5.0 \mathrm{~V}$ at different wavelengths ranging from 250 to $630 \mathrm{~nm}$. The inset is optical absorption spectrum. Reproduced with permission from Ref. [49]; 2013, Wiley; (c) Schematic diagram of the structure of $\mathrm{SnO}_{2}-\mathrm{TiO}_{2}$ photodetector; (d) Time response of $\mathrm{SnO}_{2}-\mathrm{TiO}_{2}$ photodetector under $40 \mathrm{~mW} / \mathrm{cm}^{2} \mathrm{UV}$ light (365 nm) illumination. Reproduced with permission from Ref. [56]; 2014, Elsevier. 
A self-powered UV photodetector, that is, a UV photodetector without an external power supply, is not only small in size and light in weight, but also environmentally friendly and energy efficient [57,58], and it is particularly attractive in application environments where power systems are difficult to reach, such as seabed oil spill monitoring, forest fire prevention and control, etc. [59]. Gao et al. used a solution method to grow a layer of $\mathrm{SnO}_{2}$ nanosheets on a 2.2-mm-thick FTO, then deposited a layer of $\mathrm{TiO}_{2}$, and finally assembled a photoelectrochemical, self-powered UV photodetector based on the $\mathrm{SnO}_{2}-\mathrm{TiO}_{2}$ core-shell structure [56]. Compared with the previously reported photodetectors based on nano- $\mathrm{TiO}_{2}$ film $(0.08 \mathrm{~s}$ and $0.03 \mathrm{~s})$ [60] and the $\mathrm{ZnO} / \mathrm{TiO}_{2}$ core-shell structure $(0.02 \mathrm{~s}$ and $0.009 \mathrm{~s})$ [61], the response of the device is faster $(0.02 \mathrm{~s} / 0.004 \mathrm{~s})$, as shown in Figure $2 \mathrm{~d}$. In addition, the spectral response peak of the $\mathrm{SnO}_{2}-\mathrm{TiO}_{2}$ core-shell UV photodetector is $0.6 \mathrm{~A} / \mathrm{W}$, which is located at $330 \mathrm{~nm}$.

The use of organic-inorganic composite materials to prepare UV photodetectors is a popular direction. There are various reports on the use of suitable organic materials to modify the surface of $\mathrm{SnO}_{2}$ nanostructured films $[62,63]$, and the purpose is generally to build a PN junction, reduce dark current, and broaden the spectral response range of $\mathrm{SnO}_{2}$ photodetectors. Among them, graphene is a material that can be applied to photoelectrons and photodetectors $[64,65]$, and the work function of graphene is generally smaller than that of $\mathrm{SnO}_{2}$, which avoids the generation of electronic barrier regions, so that the transfer of carriers between them produces a synergistic effect [66]. Singh et al. used hydrothermally grown $\mathrm{SnO}_{2}$ nanowires and reduced graphene oxide (rGO) to prepare a UV photodetector, and the transmittance of the device in the visible light range is only between $30 \%$ and $40 \%$ [67]. Under the voltage of $3 \mathrm{~V}$, the dark current of the device is only $2 \mathrm{nA}$, and the photocurrent increased by 2 orders of magnitude compared to the dark current. The work function of GNWs (4.5 eV) [68] is smaller than that of $\mathrm{SnO}_{2}(4.9 \mathrm{eV})$ [69], and the contact between GNWs and $\mathrm{SnO}_{2}$ causes the energy band at the interface to be bent, and an electron accumulation layer is generated. When a photo-generated electron-hole pair is generated, it is separated by the built-in electric field, and the photo-generated electron is quickly collected by GNWs, reducing the probability of being trapped by $\mathrm{SnO}_{2}$ defects. $\mathrm{SnO}_{2}$ is mainly responsible for the generation of light-generated charges, while GNWs play an important role in the efficient separation and rapid transport of light-generated charges [48]. Although the use of graphene has replaced the role of p-type materials to a certain extent, the UV detection performance of the device has been improved to a certain extent. However, due to the small forbidden band width of graphene, the transparency of such UV photodetectors made of composite materials is generally worse than that of all-metal oxide UV photodetectors.

\section{Flexible $\mathrm{SnO}_{2}$ UV Photodetector}

Flexible electronic devices have many potential applications, such as flexible mobile phones, smart fabrics, artificial skins, epidermal electronic products, and other products due to being bendable, foldable, and stretchable. In order to meet people's needs for protection and the monitoring of ultraviolet radiation and the portability of electronic protection products, UV photodetectors are required in complex environments such as human skin, and so the devices are required to be stable and have good durability under deformation. Therefore, it is necessary to prepare a high-performance, flexible UV photodetector.

Flexible substrates generally include polyimide (PI), polyethylene naphthalate (PEN), carbon cloth, etc., and are often selected for sensing applications. With the heterojunction structure of one-dimensional materials, it is difficult to achieve good interface contact and uniform assembly of two one-dimensional nanomaterials due to the limitation of material size. Javey and his team proposed a contact printing method, as shown in Figure 3, which can achieve dense assembly with high uniformity and reproducibility [70]. Based on the contact printing method, Ha et al. prepared a single-walled carbon nanotube (SWCNT) $/ \mathrm{SnO}_{2}$ Nanowire heterojunction on a PI substrate [71]. The $\mathrm{I}_{\mathrm{ph}} / \mathrm{I}_{\text {dark }}$ of the device under reverse bias reached $10^{4}$, indicating that it has a certain application potential in UV 
photodetectors. The proposal of this printing method provides a feasible solution for the large-area and uniform preparation of nano-structured UV photodetectors.

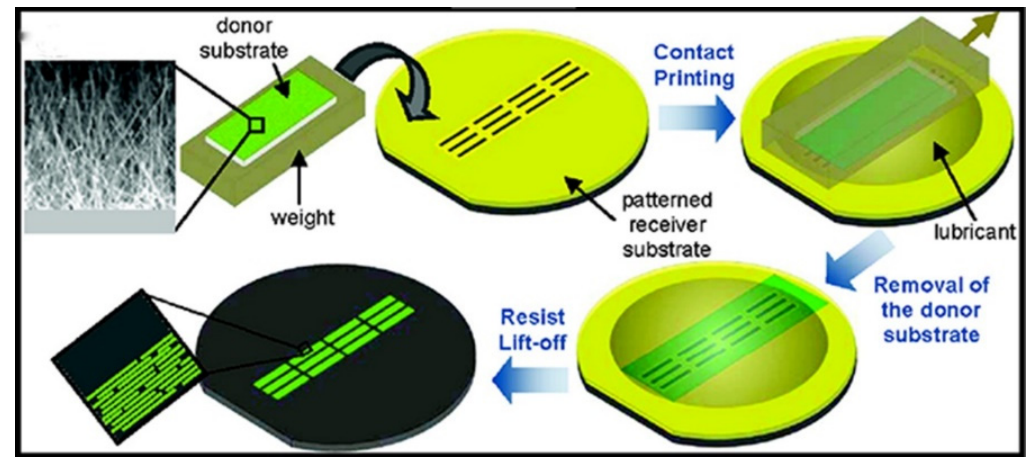

Figure 3. Schematic of the process flow for contact printing. Reprinted with permission from [70]. Copyright 2007 American Chemical Society.

Using Au catalysis, Deng et al. deposited a uniform $\mathrm{SnO}_{2}$ nanoparticle film on a carbon cloth template by atomic layer deposition and obtained $\mathrm{SnO}_{2}$ nanowire arrays by vapor transport deposition [72]. It can be seen from Figure 4a that the length of these nanowires was about $5 \mu \mathrm{m}$, and they were arranged vertically on the surface of the $\mathrm{SnO}_{2}$ layer. In the case where no carbon cloth template, $\mathrm{SnO}_{2}$ nanowire array hierarchy remained intact, as seen in the illustration in Figure 4a since the $\mathrm{SnO}_{2}$ nanoparticle film enhances the structural stability of the device. TheSnO${ }_{2}$ nanoarray was transferred to the $\mathrm{SiO}_{2} / \mathrm{Si}$ substrate, and then $\mathrm{Au} / \mathrm{Ti}$ electrodes were deposited to form a UV photodetector. Figure $4 \mathrm{~b}$ shows the spectral response of the photodetector under a constant light intensity of $1.0 \mathrm{~V}$ bias. The device had an obvious photocurrent in the ultraviolet region. The cut-off wavelength was $\sim 350 \mathrm{~nm}$, and the responsivity was maximized at $\sim 250 \mathrm{~nm}$. Figure $4 \mathrm{c}$ shows the I-V curve of the photodetector under different wavelengths and dark conditions. Under a bias voltage of $1.0 \mathrm{~V}$, the dark current of the device was only $2.3 \mathrm{pA}$, and the photocurrent can reach $0.5 \mathrm{nA}$ irradiated the light of $350 \mathrm{~nm}$. It is generally believed that oxygen molecules adsorb to the surface of $\mathrm{SnO}_{2}$ and trap free electrons, thereby forming a low-conductivity depletion layer on the surface area. Under UV irradiation, light excites holes to migrate to the surface, and through electron-hole recombination, the electro-adsorbed oxygen ions (negatively charged) are decomposed, resulting in enhanced conductivity [73-76]. Figure $4 \mathrm{~d}$ plots the time-response curve of the photodetector. It can be seen that the rise time and decay time were both less than $0.3 \mathrm{~s}$. Such a fast response may be due to the formation of a large number of nanowire/nanowire connections in the nanostructure, which form the Schottky connection and the conduction path of electrons [77].

In flexible electronic products, unlike bendability, achieving superior stretchability is more challenging. Kim et al. reported an active stretchable $\mathrm{SnO}_{2}$ nanowire ultraviolet sensor array with an observed average photosensitivity ( $\left.\mathrm{I}_{\mathrm{UV}} / \mathrm{I}_{\text {dark }}\right)$ of $10^{5}$ under low-power UV light $\left(0.03 \mathrm{~mW} / \mathrm{cm}^{2}\right)$ and a gate bias of $-40 \mathrm{~V}$ [78]. The $\mathrm{I}_{\mathrm{dd}}$-time curve was tested under $\mathrm{V}_{\mathrm{dd}}=1 \mathrm{~V}$ and $\mathrm{V}_{\text {data }}=0 \mathrm{~V}$, and the results show that the photocurrent was saturated within $40 \mathrm{~s}$. When the UV light was turned off, the recovery time was estimated to be $10 \mathrm{~s}$. Moreover, the pre-strain of up to $23 \%$ caused by the radial deformation of the device did not degrade the performance. 


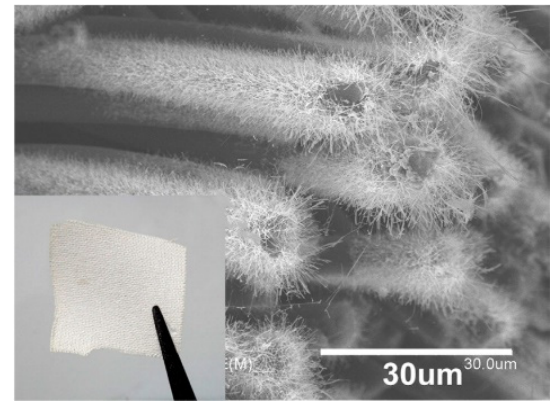

(a)

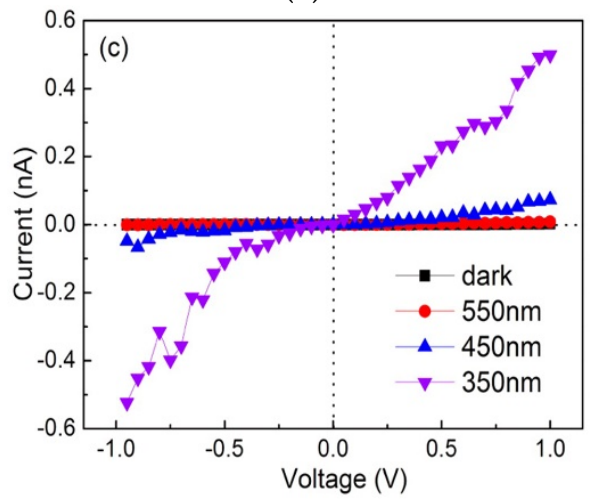

(c)

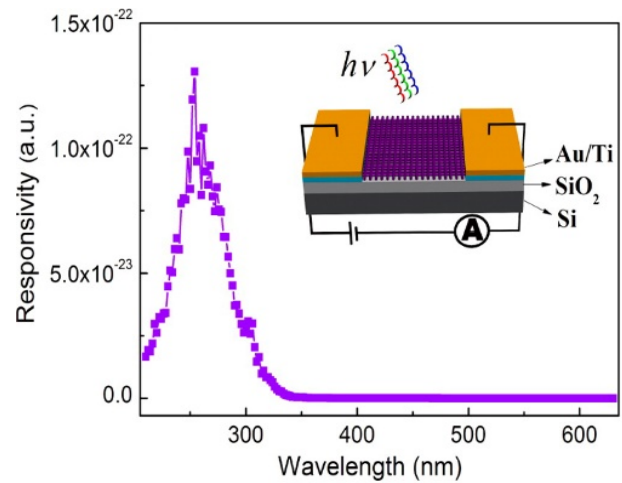

(b)

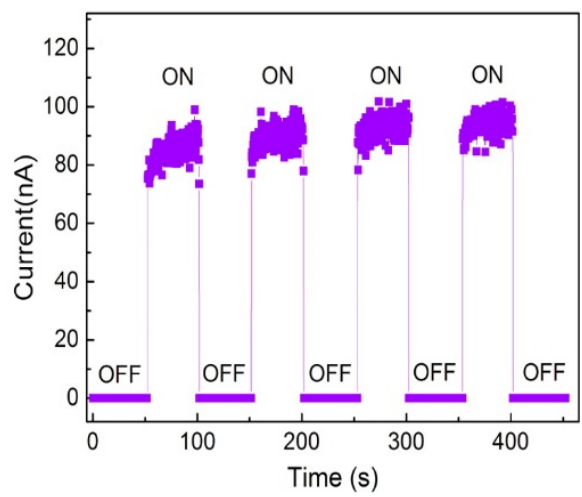

(d)

Figure 4. (a) Cross-sectional SEM image of $3 \mathrm{D} \mathrm{SnO}_{2}$ nano array; (b) Spectral response of the device; (c) I-V curves under different wavelengths and dark conditions; (d) Time-response curve of the device. Reprinted with permission from [72]. Copyright 2013 American Chemical Society.

In order to achieve good tensile properties, the structure of $\mathrm{SnO}_{2}$ nanomaterials is a good starting point. Huang et al. prepared $\mathrm{SnO}_{2}$ nanowebs with "spring" and "wave"like geometries by electrospinning, as shown in Figure 5a, and realized the preparation of a UV photodetector with superior stretchability on a polydimethylsiloxane (PDMS) substrate [79]. Experiments have shown that $\mathrm{SnO}_{2}$ nanowebs without pre-strain can be stretched to $70 \%$, and under $100 \%$ pre-strain, $\mathrm{SnO}_{2}$ nanowebs can withstand up to $160 \%$ tensile strain, and the resistance $\left(\mathrm{R} / \mathrm{R}_{0}\right)$ is only 3.1. As shown in Figure $5 b, \mathrm{SnO}_{2}$ nanowebs still maintained their structural integrity and electrical continuity after 1000 cycles at a tensile strain of $30 \%$. This excellent tensile performance can be attributed to the excellent bendability brought by the unique geometric structure of $\mathrm{SnO}_{2}$ nanowebs, and the finite element simulation results also show that bulked nanobelts can withstand large reversible strains during tension or compression. The device could be placed on the finger joint to simulate the use environment of the wearable product, as shown in Figure 5c. The device exhibits a reversible change in resistance during repeated bending cycles, and the electrical conductivity does not significantly attenuate, showing its good mechanical presence and durability. At the same time, the rise and decay times of the device in the bending and straightening state are both $12 \mathrm{~s}$ and $18 \mathrm{~s}$, and the response speed is almost negligible due to the deformation. 


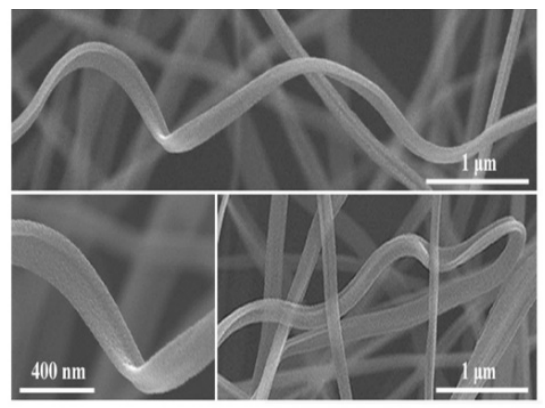

(a)

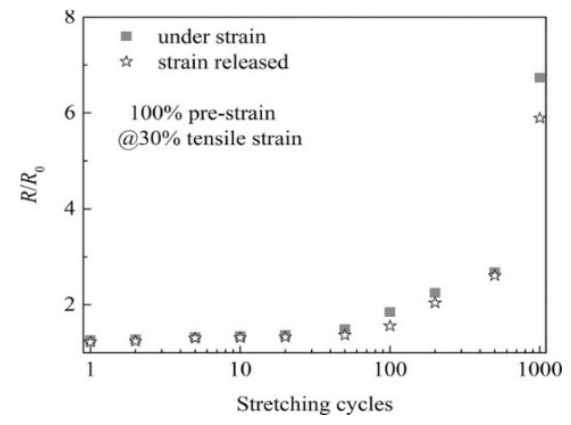

(b)

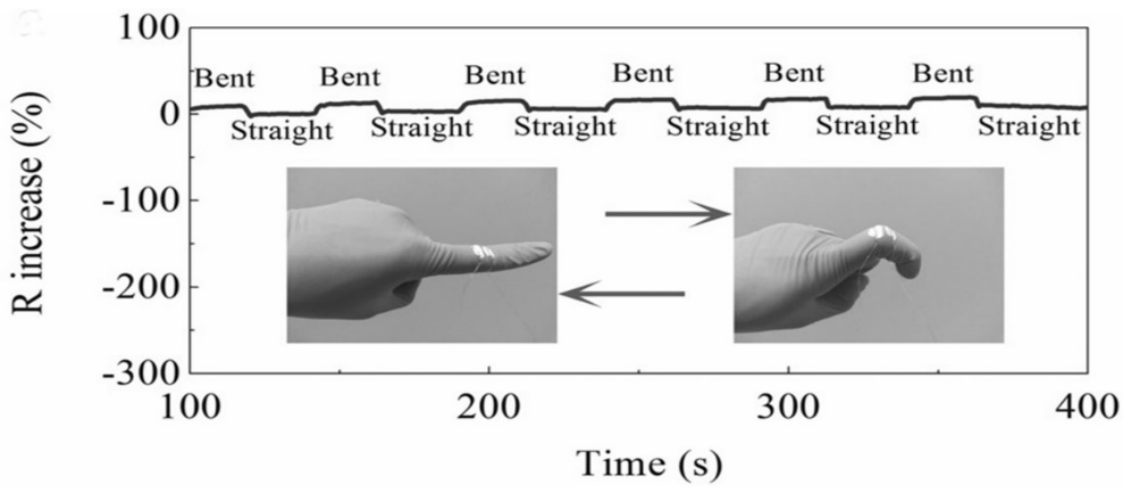

(c)

Figure 5. (a) SEM images of pre-strained $\mathrm{SnO}_{2}$ nanowebs, showing spring- (upper and lower left) and wave-like geometries (lower right); (b) R/R0 of the $\mathrm{SnO}_{2}$ nanobelt network on 100\% pre-strained PDMS as a function of stretching cycles; (c) Repeated finger bending test of wearable $\mathrm{SnO}_{2}$ photodetectors. Reproduced with permission from Ref. [79]; 2015, Wiley.

The density of defects in $\mathrm{SnO}_{2}$ is difficult to control, which makes it difficult for the electrical characteristics of $\mathrm{SnO}_{2}$ to meet the requirements of devices. Doping can effectively overcome this problem, so as to realize the adjustment of its electrical and optical characteristics [80]. Shahid et al. reported a flexible and transparent $\mathrm{Pt} / \mathrm{In}-\mathrm{SnO}_{2}$ nanobelt/Pt UV light photodetector based on an In-doped $\mathrm{SnO}_{2}$ nanobelt [81]. When the doping concentration is $3 \mathrm{wt} . \%$, the dark current is $4.7 \mathrm{nA}$, the photocurrent is $49.6 \mu \mathrm{A}$ under the irradiation of light with a wavelength of $254 \mathrm{~nm}$ and a density of $0.97 \mathrm{~mW} / \mathrm{cm}^{2}$, and the highest light sensitivity is $\sim 10^{4}$, while the light sensitivity of pure $\mathrm{SnO}_{2}$ nanobelt is estimated to be only about $\sim 143$. If the diameter of the crystal grain is equivalent to 2 times Debye length, then high sensitivity can be obtained, because the carriers will be localized on the surface of the nanomaterial, and the surface carriers can be captured by the dopant [82]. Additionally, the Debye length of $\mathrm{SnO}_{2}$ is about $3.07 \mathrm{~nm}$ according to calculations. Compared with the un-doped $\mathrm{SnO}_{2}$ nanoribbons with a grain size of $10.5 \mathrm{~nm}$, the crystal grain size of the $\mathrm{SnO}_{2}$ nanobelts doped with $3 \mathrm{wt} . \% \mathrm{In}^{3+}$ is reduced to $5.6 \mathrm{~nm}$, which may be the reason for the increased photosensitivity of $\mathrm{SnO}_{2}$ nanobelts. In addition, the increase in photosensitivity can also be attributed to the decrease of the electron balance density by doping $\mathrm{In}^{3+}$ in $\mathrm{SnO}_{2}$, which leads to an increase in oxygen adsorption on the surface of the nanobelt.

In addition, the author also tested the flexibility of the device. When the strain increased from $0 \%$ to $0.625 \%$, the photocurrent of the device decreased very little. Moreover, when the strain increased to 1.66 strain $\%$, compared with $0 \%$ strain, the photocurrent was only reduced by about $45 \%$. In addition, after the device was bent to a radius of $8 \mathrm{~mm}$ ( $0.83 \%$ strain) for 300 bending cycles, the conductivity and response speed were less affected, showing excellent stability. 
Table 2 summarizes the research progress of transparent and flexible $\mathrm{SnO}_{2} \mathrm{UV}$ photodetectors.

Table 2. Comparison of the parameters of various photodetectors.

\begin{tabular}{|c|c|c|c|c|c|c|}
\hline Material & $\begin{array}{l}\text { Transparency } \\
(380-780 \mathrm{~nm})\end{array}$ & Flexible/Substrate & Dark Current & $\begin{array}{l}\text { Responsivity } \\
\text { (A/W) }\end{array}$ & Response Time & Ref. \\
\hline $\mathrm{ZnO} / \mathrm{SnO}_{2} \mathrm{NFs}$ & $>80 \%$ & - & $1.7 \mathrm{pA}$ & - & $32.2 \mathrm{~s} / 7.8 \mathrm{~s}$ & [49] \\
\hline $\mathrm{SnO}_{2} \mathrm{NBs} / \mathrm{NiO}$ & $>60 \%$ & - & - & - & $17 \mathrm{~s} / 9 \mathrm{~s}$ & [51] \\
\hline $\mathrm{SnO}_{2}-\mathrm{NiO} \mathrm{NFs}$ & $>85 \%$ & - & - & 8.67 & $8 \mathrm{~s} /-$ & [52] \\
\hline $\mathrm{SnO}_{2} \mathrm{NS}-\mathrm{TiO}_{2}$ & $>60 \%$ & - & - & 0.6 & $20 \mathrm{~ms} / 4 \mathrm{~ms}$ & [56] \\
\hline $\mathrm{SnO}_{2} \mathrm{NW} / \mathrm{rGO}$ & $>30 \%$ & - & $2 \mathrm{nA}$ & - & - & [67] \\
\hline $\mathrm{SWCNT} / \mathrm{SnO}_{2} \mathrm{NW}$ & - & PI substrate & - & - & - & [71] \\
\hline $\mathrm{SnO}_{2} \mathrm{NWAs}$ & - & carbon cloth & $2.3 \mathrm{pA}$ & - & $<0.3 \mathrm{~s}$ & [72] \\
\hline $\mathrm{SnO}_{2} \mathrm{NW}$ device array & - & $23 \%$ pre-strain & $2 \mathrm{pA}$ & - & $40 \mathrm{~s} / 10 \mathrm{~s}$ & [78] \\
\hline $\mathrm{SnO}_{2}$ nanowebs & $>70 \%$ & $160 \%$ tensile strain & - & - & $12 \mathrm{~s} / 18 \mathrm{~s}$ & [79] \\
\hline $\mathrm{In}-\mathrm{SnO}_{2} \mathrm{NB}$ & - & $0.83 \%$ strain & $4.7 \mathrm{nA}$ & - & $-/<0.175 \mathrm{~s}$ & [81] \\
\hline
\end{tabular}

\section{Optimization}

To realize a flexible and transparent UV photodetector based on $\mathrm{SnO}_{2}$, one firstly needs to prepare a high-performance $\mathrm{SnO}_{2} \mathrm{UV}$ photodetector. Compared with other popular metal oxide materials for preparing UV photodetectors, the surface of $\mathrm{SnO}_{2}$ has more defect states, which makes it easier for UV photodetectors based on $\mathrm{SnO}_{2}$ materials to obtain higher gains, but this also means that the optimization of parameters such as dark current and response time will be more difficult. Although methods such as improving crystallinity and constructing a core-shell structure have been adopted to prepare UV photodetectors with superior performance, further improvements are still needed to overcome more complex and diverse application environments.

The defects in $\mathrm{SnO}_{2}$ are mainly oxygen vacancies and lattice defects which are difficult to control, and research has found that doping can effectively solve these problems. On the one hand, the introduction of excess impurities can improve the crystallinity of $\mathrm{SnO}_{2}$, reduce the scattering effect, affect the size of the crystal grains, and thus have a positive impact on the UV response of the device [83]. According to previous reports, introducing $\mathrm{Zr}^{4+}$ as a dopant can control the crystallinity of $\mathrm{SnO}_{2}$ [84]. When the $\mathrm{Zr}^{4+}$ doping content changes from 0 at. $\%$ to 3 at. $\%$, the $\mathrm{SnO}_{2}$ grain size can increase from $10.213 \mathrm{~nm}$ to $11.315 \mathrm{~nm}$; however, when the doping content continues to increase to 10 at.\%, the crystallinity of $\mathrm{SnO}_{2}$ becomes worse, and the grain size decreases to $8.644 \mathrm{~nm}$. On the other hand, the selection of appropriate dopants can achieve the suppression of oxygen vacancies, further reduce the dark current of the device, and increase the gain of the device. The main requirements for this dopant are as follows $[85,86]$ : the bonding strength of the doping element and oxygen should be higher than the bonding strength of tin and oxygen; the size of the dopant should be smaller than the tin ion; and the high Lewis acid strength should be higher.

In order to solve the problem of a slow response time, the UV photodetector with a PN structure has attracted wide attention. Among them is the use of the core-shell structure, which not only optimizes the response speed of $\mathrm{SnO}_{2} \mathrm{UV}$ photodetectors, but also is expected to be applied to self-powered devices to expand the application environment of $\mathrm{SnO}_{2} \mathrm{UV}$ photodetectors. At present, $\mathrm{Au}$, etc. materials are usually used as electrodes [87] in order to build Schottky $\mathrm{SnO}_{2} \mathrm{UV}$ photodetectors. Generally, the contact between the two metal electrodes of the Schottky detector and the semiconductor layer can be divided into an ohmic contact side and a Schottky contact side. A built-in electric field (depletion region) is formed at the interface of Schottky contact, which can also enable the photogenerated carriers to be effectively separated on the interface. Moreover, Schottky-type devices generally do not require a p-type semiconductor functional layer, thus avoiding the influence of interface defect states caused by the mismatch of the $n$-type layer and the $\mathrm{p}$ type layer material lattice, thermal expansion coefficient, etc., which is beneficial to reduce 
the probability of photo-generated carriers being captured, and the mobility of photogenerated carriers at the interface of the device is improved, thereby increasing the rate at which the photo-generated carriers are collected by the electrode, so that the response time is improved. Therefore, in theory, a UV detector based on the Schottky structure could also improve the response speed of the device. However, there are relatively few reports on Schottky contacts, which may be due to fewer electrodes with suitable metals and alloys.

The combination of organic-inorganic materials has always been a hot research field. The application of this hybrid structure is expected to combine the advantages of inorganic semiconductors and organic polymer semiconductors, integrating high electron mobility, good p-type conductivity, and low-cost solution processing, making mass production possible [88]. $\mathrm{SnO}_{2}$ nanomaterials can be modified with organics to achieve surface modification of $\mathrm{SnO}_{2}$ and reduce band bending caused by oxygen adsorption; it can also be prepared from organics, such as water-oil interface assembly [89], etc., to reduce preparation costs.

In recent years, surface plasmon (SP) has been considered to be one of the effective methods to improve the sensitivity of semiconductor-based UV photodetectors [90]. The principle is that when the resonance wavelength of the surface plasmon is consistent with the response wavelength of the UV detector, coupling oscillation will occur, and the spectral response will increase significantly. Metal nanoparticles such as aluminum and silver can be selected as plasma to be deposited on the top of the device. However, there are few studies on the application of surface plasmons to UV photodetectors, and further research is needed on the mechanism, repeatability, and assembly of surface plasmons.

In terms of preparation methods, most of the current methods for preparing $\mathrm{SnO}_{2}$ UV photodetectors use atomic layer deposition, electrospinning, hydrothermal methods, etc. $[47,87,91]$, which are relatively difficult to apply to large-area uniform preparation. With the maturity of inkjet printing technology, its advantages such as precise patterning and large-area preparation have aroused the interest of many scholars, and there are more and more reports on inkjet printing $\mathrm{SnO}_{2}$ sensors [92-94]. However, the main difficulties at present mostly involve preparing suitable printable inks and lowering the sintering temperature. For inkjet printing technology, it is crucially important to adjust the ink viscosity, surface tension and other characteristics to meet the requirements of printing equipment, and in most cases, it is necessary to use suitable additives to solve the problem of uneven film, so that the printed film has good uniformity. Studies have shown that if general annealing technologies, such as hot stage annealing, etc., are used to remove organic matter and other impurities in the film prepared by the solution methods, $\mathrm{SnO}_{2}$ annealing at $350^{\circ} \mathrm{C}$ and below is generally amorphous. If the better crystallinity is required, the annealing temperature must be greater than $350{ }^{\circ} \mathrm{C}$, or even $500{ }^{\circ} \mathrm{C}$ and above $[95,96]$. However, the glass transition temperature of flexible plastic substrates is generally less than $400{ }^{\circ} \mathrm{C}$ [97]. For example, the glass transition temperatures of commonly used polyethylene terephthalate (PET), polyethylene naphthalate (PEN), and polyimide (PI) are $80^{\circ} \mathrm{C}, 120^{\circ} \mathrm{C}$, and $360^{\circ} \mathrm{C} \sim 400^{\circ} \mathrm{C}$, respectively. By lowering the sintering temperature to adapt to the flexible substrate, it is possible to expand the application of $\mathrm{SnO}_{2}$ ultraviolet photodetectors prepared by inkjet printing in flexible electronic devices.

\section{Summary}

In this review, the concept and understanding of the basic parameters of photodetectors are reviewed, and the operating mechanism of $\mathrm{SnO}_{2} \mathrm{UV}$ photodetectors and various influencing factors are discussed. The research progress of UV photodetectors based on transparent and flexible $\mathrm{SnO}_{2}$ is summarized, which provides key insights for the further development of $\mathrm{SnO}_{2} \mathrm{UV}$ photodetectors in flexible electronic products. $\mathrm{SnO}_{2}$ has many excellent characteristics, such as excellent stability and transparency, low material cost, etc., and is also often used in various optoelectronic devices. However, there are relatively few studies on the application of $\mathrm{SnO}_{2}$ materials in UV photodetectors, and it is hoped that this review will stimulate the research on $\mathrm{SnO}_{2}$ materials. 
Author Contributions: Funding acquisition, H.N., R.Y., J.P., and Z.X.; resources, J.P. and X.L.; investigation, Q.Y. and X.Z.; data curation, Q.Y., W.Z., and C.G.; writing-original draft preparation, Q.Y. and X.Z.; writing-review and editing, H.N., R.Y., and D.L.; project administration, Z.X. and R.Y. All authors have read and agreed to the published version of the manuscript.

Funding: This work was supported by the Science Foundation of Yulin Normal University (No. G2020ZK01), Key-Area Research and Development Program of Guangdong Province (No.2020B010183 002), National Natural Science Foundation of China (Grant No.62074059 and 22090024), Guangdong Major Project of Basic and Applied Basic Research (No.2019B030302007), Fundamental Research Funds for the Central Universities (No.2020ZYGXZR060), Ji Hua Laboratory scientific research project (X190221TF191), 2021 Guangdong University Student Science, Technology Innovation Special Fund ("Climbing Plan" Special Fund) (No.pdjh2021b0036), and College Students Innovation and Entrepreneurship Training Program (No.S202110561184).

Data Availability Statement: Not applicable.

Conflicts of Interest: The authors declare no conflict of interest.

\section{References}

1. Game, O.; Singh, U.; Kumari, T.; Banpurkar, A.; Ogale, S. ZnO(N)-Spiro-MeOTAD hybrid photodiode: An efficient self-powered fast-response UV (visible) photosensor. Nanoscale 2014, 6, 503-513. [CrossRef]

2. Fu, Q.; Peng, J.; Yao, Z.; Zhao, H.; Ma, Z.; Tao, H.; Tu, Y.; Tian, Y.; Zhou, D.; Han, Y. Highly sensitive ultraviolet photodetectors based on $\mathrm{ZnO} / \mathrm{SnO}_{2}$ core-shell nanorod arrays. Appl. Surf. Sci. 2020, 527, 146923. [CrossRef]

3. Mohammadi, S.; Zavvari, M. High performance n-ZnO/p-metal-oxides UV detector grown in low-temperature aqueous solution bath. Thin Solid Films 2017, 626, 173-177. [CrossRef]

4. Bie, Y.; Liao, Z.; Zhang, H.; Li, G.; Ye, Y.; Zhou, Y.; Xu, J.; Qin, Z.; Dai, L.; Yu, D. Self-Powered, Ultrafast, Visible-Blind UV Detection and Optical Logical Operation based on ZnO/GaN Nanoscale p-n Junctions. Adv. Mater. 2011, 23, 649-653. [CrossRef] [PubMed]

5. Xie, C.; Nie, B.; Zeng, L.; Liang, F.; Wang, M.; Luo, L.; Feng, M.; Yu, Y.; Wu, C.; Wu, Y.; et al. Core-Shell Heterojunction of Silicon Nanowire Arrays and Carbon Quantum Dots for Photovoltaic Devices and Self-Driven Photodetectors. ACS Nano 2014, 8 , 4015-4022. [CrossRef] [PubMed]

6. Zhai, T.; Li, L.; Wang, X.; Fang, X.; Bando, Y.; Golberg, D. Recent Developments in One-Dimensional Inorganic Nanostructures for Photodetectors. Adv. Funct. Mater. 2010, 20, 4233-4248. [CrossRef]

7. Han, S.; Peng, H.; Sun, Q.; Venkatesh, S.; Chung, K.; Lau, S.C.; Zhou, Y.; Roy, V.A.L. An Overview of the Development of Flexible Sensors. Adv. Mater. 2017, 29, 1700375. [CrossRef]

8. Xu, Y.; Lin, Q. Photodetectors based on solution-processable semiconductors: Recent advances and perspectives. Appl. Phys. Rev. 2020, 7, 11315. [CrossRef]

9. Zou, Y.; Zhang, Y.; Hu, Y.; Gu, H. Ultraviolet Detectors Based on Wide Bandgap Semiconductor Nanowire: A Review. Sensors 2018, 18, 2072. [CrossRef]

10. Nasiri, N.; Jin, D.; Tricoli, A. Nanoarchitechtonics of Visible-Blind Ultraviolet Photodetector Materials: Critical Features and Nano-Microfabrication. Adv. Opt. Mater. 2019, 7, 1800580. [CrossRef]

11. Shieh, J.; Lai, Y.; Ni, W.; Kuo, H.; Fang, C.; Huang, J.Y.; Pan, C. Enhanced photoresponse of a metal-oxide-semiconductor photodetector with silicon nanocrystals embedded in the oxide layer. Appl. Phys. Lett. 2007, 90, 51105. [CrossRef]

12. Patel, M.; Kim, H.; Kim, J. All Transparent Metal Oxide Ultraviolet Photodetector. Adv. Electron. Mater. $2015,1,1500232$. [CrossRef]

13. Fang, Y.K.; Hwang, S.B.; Chen, K.H.; Liu, C.R.; Tsai, M.J.; Kuo, L.C. An amorphous SiC/Si heterojunction p-i-n diode for low-noise and high-sensitivity UV detector. IEEE Trans. Electron. Dev. 1992, 39, 292-296. [CrossRef]

14. Chen, X.; Zhu, H.; Cai, J.; Wu, Z. High-performance 4H-SiC-based ultraviolet p-i-n photodetector. J. Appl. Phys. 2007, 102, 24505. [CrossRef]

15. Luo, J.; Li, S.; Wu, H.; Zhou, Y.; Li, Y.; Liu, J.; Li, J.; Li, K.; Yi, F.; Niu, G.; et al. $\mathrm{Cs}_{2} \mathrm{AgInCl}_{6}$ Double Perovskite Single Crystals: Parity Forbidden Transitions and Their Application For Sensitive and Fast UV Photodetectors. ACS Photonics 2018, 5, 398-405. [CrossRef]

16. Zhang, Y.; Liu, Y.; Xu, Z.; Ye, H.; Li, Q.; Hu, M.; Yang, Z.; Liu, S.F. Two-dimensional (PEA) ${ }_{2} \mathrm{PbBr}_{4}$ perovskite single crystals for a high performance UV-detector. J. Mater. Chem. C Mater. Opt. Electron. Devices 2019, 7, 1584-1591. [CrossRef]

17. Bo, R.; Nasiri, N.; Chen, H.; Caputo, D.; Fu, L.; Tricoli, A. Low-Voltage High-Performance UV Photodetectors: An Interplay between Grain Boundaries and Debye Length. ACS Appl. Mater. Interfaces 2017, 9, 2606-2615. [CrossRef]

18. Zhao, B.; Wang, F.; Chen, H.; Zheng, L.; Su, L.; Zhao, D.; Fang, X. An Ultrahigh Responsivity $\left(9.7\right.$ mA W $\left.{ }^{-1}\right)$ Self-Powered Solar-Blind Photodetector Based on Individual $\mathrm{ZnO}-\mathrm{Ga}_{2} \mathrm{O}_{3}$ Heterostructures. Adv. Funct Mater. 2017, 27, 1700264. [CrossRef]

19. Nasiri, N.; Bo, R.; Fu, L.; Tricoli, A. Three-dimensional nano-heterojunction networks: A highly performing structure for fast visible-blind UV photodetectors. Nanoscale 2017, 9, 2059-2067. [CrossRef] 
20. Li, P.; Shi, H.; Chen, K.; Guo, D.; Cui, W.; Zhi, Y.; Wang, S.; Wu, Z.; Chen, Z.; Tang, W. Construction of GaN/Ga $2 \mathrm{O}_{3}$ p-n junction for an extremely high responsivity self-powered UV photodetector. J. Mater. Chem. C Mater. Opt. Electron. Devices 2017, 5, 1157-1562. [CrossRef]

21. Pargoletti, E.; Hossain, U.H.; Di Bernardo, I.; Chen, H.; Tran-Phu, T.; Chiarello, G.L.; Lipton-Duffin, J.; Pifferi, V.; Tricoli, A.; Cappelletti, G. Engineering of $\mathrm{SnO}_{2}$-Graphene Oxide Nanoheterojunctions for Selective Room-Temperature Chemical Sensing and Optoelectronic Devices. ACS Appl. Mater. Interfaces 2020, 12, 39549-39560. [CrossRef]

22. Pargoletti, E.; Hossain, U.H.; Di Bernardo, I.; Chen, H.; Tran-Phu, T.; Lipton-Duffin, J.; Cappelletti, G.; Tricoli, A. Roomtemperature photodetectors and VOC sensors based on graphene oxide-ZnO nano-heterojunctions. Nanoscale 2019, 11, 2293222945. [CrossRef] [PubMed]

23. Kumar, S.; Pratiyush, A.S.; Dolmanan, S.B.; Tripathy, S.; Muralidharan, R.; Nath, D.N. UV detector based on InAlN/GaN-on-Si HEMT stack with photo-to-dark current ratio > 107. Appl. Phys. Lett. 2017, 111, 251103. [CrossRef]

24. Dang, V.Q.; Trung, T.Q.; Duy, L.T.; Kim, B.; Siddiqui, S.; Lee, W.; Lee, N. High-Performance Flexible Ultraviolet (UV) Phototransistor Using Hybrid Channel of Vertical ZnO Nanorods and Graphene. ACS Appl. Mater. Interfaces 2015, 7, 11032-11040. [CrossRef] [PubMed]

25. Lu, M.; Weng, T.; Chen, J.; Chen, Y. Ultrahigh-gain single $\mathrm{SnO}_{2}$ nanowire photodetectors made with ferromagnetic nickel electrodes. Npg Asia Mater. 2012, 4, e26. [CrossRef]

26. Sheng Pan, S.; Fung Yu, S.; Xia Zhang, Y.; Yuan Luo, Y.; Wang, S.; Min Xu, J.; Hai Li, G. Crystallite size-modulated exciton emission in $\mathrm{SnO}_{2}$ nanocrystalline films grown by sputtering. J. Appl. Phys. 2013, 113, 143104. [CrossRef]

27. Xu, S.; Zhao, H.; Xu, Y.; Xu, R.; Lei, Y. Carrier Mobility-Dominated Gas Sensing: A Room-Temperature Gas-Sensing Mode for $\mathrm{SnO}_{2}$ Nanorod Array Sensors. ACS Appl. Mater. Interfaces 2018, 10, 13895-13902. [CrossRef]

28. Yang, H.Y.; Yu, S.F.; Liang, H.K.; Lau, S.P.; Pramana, S.S.; Ferraris, C.; Cheng, C.W.; Fan, H.J. Ultraviolet Electroluminescence from Randomly Assembledn - $\mathrm{SnO}_{2}$ Nanowiresp-GaN: Mg Heterojunction. ACS Appl. Mater. Interfaces 2010, 2, 1191-1194. [CrossRef]

29. Liu, R.; Chen, Y.; Wang, F.; Cao, L.; Pan, A.; Yang, G.; Wang, T.; Zou, B. Stimulated emission from trapped excitons in $\mathrm{SnO}_{2}$ nanowires. Phys. E Low-Dimens. Syst. Nanostruct. 2007, 39, 223-229. [CrossRef]

30. Lin, C.; Chen, R.; Chen, T.; Chen, H.; Chen, Y.; Chen, K.; Chen, L. High photocurrent gain in SnO 2 nanowires. Appl. Phys. Lett. 2008, 93, 112115. [CrossRef]

31. Das Mahapatra, A.; Basak, D. Investigation on sub-band gap defects aided UV to NIR broad-band low-intensity photodetection by $\mathrm{SnO}_{2}$ thin film. Sens. Actuators A Phys. 2020, 312, 112168. [CrossRef]

32. Bouznit, Y.; Henni, A. Characterization of $\mathrm{Sb}$ doped $\mathrm{SnO}_{2}$ films prepared by spray technique and their application to photocurrent generation. Mater. Chem. Phys. 2019, 233, 242-248. [CrossRef]

33. Wu, J.; Kuo, C. Ultraviolet photodetectors made from $\mathrm{SnO}_{2}$ nanowires. Thin Solid Films 2009, 517, 3870-3873. [CrossRef]

34. Lou, Z.; Yang, X.; Chen, H.; Liang, Z. Flexible ultraviolet photodetectors based on $\mathrm{ZnO}-\mathrm{SnO}_{2}$ heterojunction nanowire arrays. J. Semicond. 2018, 39, 24002. [CrossRef]

35. Chen, Y.; Zhu, C.; Cao, M.; Wang, T. Photoresponse of $\mathrm{SnO}_{2}$ nanobelts grown in situ on interdigital electrodes. Nanotechnology 2007, 18, 285502. [CrossRef]

36. Kaur, D.; Kumar, M. A Strategic Review on Gallium Oxide Based Deep-Ultraviolet Photodetectors: Recent Progress and Future Prospects. Adv. Opt. Mater. 2021, 9, 2002160. [CrossRef]

37. Huang, C.; Li, W.; Hsiao, Y.; Gao, W.; Chen, C. Trap-assisted photomultiplication in a-IGZO/p-Si heterojunction ultraviolet photodiodes. Smart Mater. Struct. 2020, 29, 115019. [CrossRef]

38. Creeden, J.A.; Madaras, S.E.; Beringer, D.B.; Novikova, I.; Lukaszew, R.A. Growth and Characterization of Vanadium Dioxide/Niobium Doped Titanium Dioxide Heterostructures for Ultraviolet Detection. Adv. Opt. Mater. 2019, 7, 1901143. [CrossRef]

39. Teng, F.; Hu, K.; Ouyang, W.; Fang, X. Photoelectric Detectors Based on Inorganic p-Type Semiconductor Materials. Adv. Mater. 2018, 30, 1706262. [CrossRef]

40. Konstantatos, G.; Badioli, M.; Gaudreau, L.; Osmond, J.; Bernechea, M.; de Arquer FP, G.; Gatti, F.; Koppens, F.H.L. Hybrid graphene-quantum dot phototransistors with ultrahigh gain. Nat. Nanotechnol. 2012, 7, 363-368. [CrossRef]

41. McIntyre, R.J. Recent developments in silicon avalanche photodiodes. Measurement 1985, 3, 146-152. [CrossRef]

42. Zhai, T.; Fang, X.; Liao, M.; Xu, X.; Zeng, H.; Yoshio, B.; Golberg, D. A Comprehensive Review of One-Dimensional Metal-Oxide Nanostructure Photodetectors. Sensors 2009, 9, 6504-6529. [CrossRef] [PubMed]

43. Kim, W.; Chu, K.S. ZnO nanowire field-effect transistor as a UV photodetector; optimization for maximum sensitivity. Phys. Status Solidi A 2009, 206, 179-182. [CrossRef]

44. Lien, D.H.; Retamal, J.R.; Ke, J.J.; Kang, C.F.; He, J.H. Surface effects in metal oxide-based nanodevices. Nanoscale 2015, 7, 19874-19884. [CrossRef]

45. Zheng, J.; Cheng, B.; Wu, F.; Su, X.; Xiao, Y.; Guo, R.; Lei, S. Modulation of Surface Trap Induced Resistive Switching by Electrode Annealing in Individual PbS Micro/Nanowire-Based Devices for Resistance Random Access Memory. ACS Appl. Mater. Interfaces 2014, 6, 20812-20818. [CrossRef]

46. Özer, M.; Yıldız, D.E.; Altındal, Ş.; Bülbül, M.M. Temperature dependence of characteristic parameters of the $\mathrm{Au} / \mathrm{SnO} 2 / \mathrm{n}-\mathrm{Si}$ (MIS) Schottky diodes. Solid-State Electron. 2007, 51, 941-949. [CrossRef]

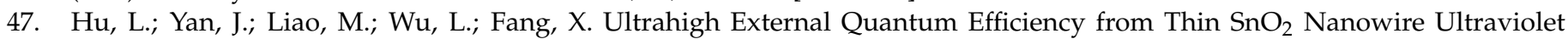
Photodetectors. Small 2011, 7, 1012-1017. [CrossRef] [PubMed] 
48. Lan, G.; Nong, J.; Jin, W.; Zhu, R.; Luo, P.; Jiang, H.; Wei, W. Enhanced UV photoresponse employing 3D graphene nanowalls/SnO 2 nanocomposite film. Surf. Coat. Technol. 2019, 359, 90-96. [CrossRef]

49. Tian, W.; Zhai, T.; Zhang, C.; Li, S.; Wang, X.; Liu, F.; Liu, D.; Cai, X.; Tsukagoshi, K.; Golberg, D.; et al. Low-Cost Fully Transparent Ultraviolet Photodetectors Based on Electrospun $\mathrm{ZnO}-\mathrm{SnO}_{2}$ Heterojunction Nanofibers. Adv. Mater. 2013, 25, 4625-4630. [CrossRef]

50. Hsu, C.; Lu, Y. Fabrication of a transparent ultraviolet detector by using n-type $\mathrm{Ga}_{2} \mathrm{O}_{3}$ and p-type Ga-doped SnO $\mathrm{O}_{2}$ core-shell nanowires. Nanoscale 2012, 4, 571-5717. [CrossRef]

51. Huang, S.; Wu, H.; Matsubara, K.; Cheng, J.; Pan, W. Facile assembly of n-SnO ${ }_{2}$ nanobelts-p-NiO heterojunctions with enhanced ultraviolet photoresponse. Chem. Commun. 2014, 50, 2847-2850. [CrossRef] [PubMed]

52. Long, Z.; Xu, X.; Yang, W.; Hu, M.; Shtansky, D.V.; Golberg, D.; Fang, X. Cross-Bar $\mathrm{SnO}_{2}-\mathrm{NiO}$ Nanofiber-Array-Based Transparent Photodetectors with High Detectivity. Adv. Electron. Mater. 2020, 6, 1901048. [CrossRef]

53. Zhang, W.; Chuu, C.; Huang, J.; Chen, C.; Tsai, M.; Chang, Y.; Liang, C.; Chen, Y.; Chueh, Y.; He, J.; et al. Ultrahigh-Gain Photodetectors Based on Atomically Thin Graphene-MoS 2 Heterostructures. Sci. Rep. 2014, 4, 1-8. [CrossRef] [PubMed]

54. Kilic, C.; Zunger, A. Origins of coexistence of conductivity and transparency in $\mathrm{SnO}_{2}$. Phys. Rev. Lett. 2002, 88, 95501. [CrossRef] [PubMed]

55. Samson, S.; Fonstad, C.G. Defect structure and electronic donor levels in stannic oxide crystals. J. Appl. Phys. 1973, 44, 4618-4621. [CrossRef]

56. Gao, C.; Li, X.; Zhu, X.; Chen, L.; Wang, Y.; Teng, F.; Zhang, Z.; Duan, H.; Xie, E. High performance, self-powered UV-photodetector based on ultrathin, transparent, $\mathrm{SnO}_{2}-\mathrm{TiO}_{2}$ core-shell electrodes. J. Alloys Compd. 2014, 616, 510-515. [CrossRef]

57. Hatch, S.M.; Briscoe, J.; Dunn, S. A Self-Powered ZnO-Nanorod/CuSCN UV Photodetector Exhibiting Rapid Response. Adv. Mater. 2013, 25, 867-871. [CrossRef]

58. Qiao, H.; Huang, Z.; Ren, X.; Liu, S.; Zhang, Y.; Qi, X.; Zhang, H. Self-Powered Photodetectors Based on 2D Materials. Adv. Opt. Mater. 2020, 8, 1900765. [CrossRef]

59. Su, L.; Yang, W.; Cai, J.; Chen, H.; Fang, X. Self-Powered Ultraviolet Photodetectors Driven by Built-In Electric Field. Small 2017, 13, 1701687. [CrossRef]

60. Li, X.; Gao, C.; Duan, H.; Lu, B.; Pan, X.; Xie, E. Nanocrystalline $\mathrm{TiO}_{2}$ film based photoelectrochemical cell as self-powered UV-photodetector. Nano Energy 2012, 1, 640-645. [CrossRef]

61. Gao, C.; Li, X.; Wang, Y.; Chen, L.; Pan, X.; Zhang, Z.; Xie, E. Titanium dioxide coated zinc oxide nanostrawberry aggregates for dye-sensitized solar cell and self-powered UV-photodetector. J. Power Sources 2013, 239, 458-465. [CrossRef]

62. Mahapatra, A.D.; Basak, D. Augmented performance towards ultraviolet and visible dual-band photodetection by polyvinyl butyral coated $\mathrm{SnO}_{2}$ nanorod array film. Surf. Interfaces 2021, 26, 101342. [CrossRef]

63. Kumar, A.; Rout, L.; Dhaka, R.S.; Samal, S.L.; Dash, P. Design of a graphene oxide-SnO $\mathrm{S}_{2}$ nanocomposite with superior catalytic efficiency for the synthesis of $\beta$-enaminones and $\beta$-enaminoesters. Rsc Adv. 2015, 5, 39193-39204. [CrossRef]

64. Bonaccorso, F.; Sun, Z.; Hasan, T.; Ferrari, A.C. Graphene photonics and optoelectronics. Nat. Photonics 2010, 4, 611-622. [CrossRef]

65. Park, J.; Ahn, Y.H.; Ruiz-Vargas, C. Imaging of Photocurrent Generation and Collection in Single-Layer Graphene. Nano Lett. 2009, 9, 1742-1746. [CrossRef]

66. Shen, H.; Zhao, X.; Duan, L.; Liu, R.; Wu, H.; Hou, T.; Jiang, X.; Gao, H. Influence of interface combination of RGO-photosensitized $\mathrm{SnO}_{2} @ \mathrm{RGO}$ core-shell structures on their photocatalytic performance. Appl. Surf. Sci. 2017, 391, 627-634. [CrossRef]

67. Singh, M.K.; Pandey, R.K.; Prakash, R. High-performance photo detector based on hydrothermally grown $\mathrm{SnO}_{2}$ nanowire/reduced graphene oxide (rGO) hybrid material. Org. Electron. 2017, 50, 359-366. [CrossRef]

68. Nong, J.; Wei, W.; Song, X.; Tang, L.; Yang, J.; Sun, T.; Yu, L.; Luo, W.; Li, C.; Wei, D. Direct growth of graphene nanowalls on silica for high-performance photo-electrochemical anode. Surf. Coat. Technol. 2017, 320, 579-583. [CrossRef]

69. Tang, W.; Wang, J.; Qiao, Q.; Liu, Z.; Li, X. Mechanism for acetone sensing property of Pd-loaded $\mathrm{SnO}_{2}$ nanofibers prepared by electrospinning: Fermi-level effects. J. Mater. Sci. 2015, 50, 2605-2615. [CrossRef]

70. Fan, Z.; Ho, J.C.; Jacobson, Z.A.; Yerushalmi, R.; Alley, R.L.; Razavi, H.; Javey, A. Wafer-Scale Assembly of Highly Ordered Semiconductor Nanowire Arrays by Contact Printing. Nano Lett. 2008, 8, 20-25. [CrossRef]

71. Park, J.; Kim, Y.; Kim, G.; Ha, J.S. Facile Fabrication of SWCNT/ $\mathrm{SnO}_{2}$ Nanowire Heterojunction Devices on Flexible Polyimide Substrate. Adv. Funct. Mater. 2011, 21, 4159-4165. [CrossRef]

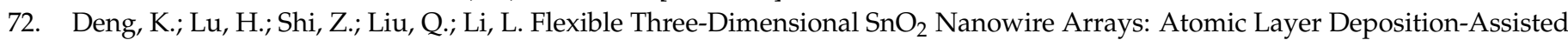
Synthesis, Excellent Photodetectors, and Field Emitters. ACS Appl. Mater. Interfaces 2013, 5, 7845-7851. [CrossRef]

73. Li, Y.; Huang, W.; Liu, H.; Wang, J.; Tian, L.; Zhang, S. UV photodetector based on polycrystalline $\mathrm{SnO}_{2}$ nanotubes by electrospinning with enhanced performance. J. Nanopart. Res. 2018, 20, 1-2. [CrossRef]

74. Jiang, J.; Heck, F.; Hofmann, D.M.; Eickhoff, M. Synthesis of $\mathrm{SnO}_{2}$ Nanowires Using $\mathrm{SnI}_{2}$ as Precursor and Their Application as High-Performance Self-Powered Ultraviolet Photodetectors. Phys. Status Solidi B 2018, 255, 1700426. [CrossRef]

75. Wang, S.; Zhao, J.; Tong, T.; Cheng, B.; Xiao, Y.; Lei, S. Bias-Controlled Tunable Electronic Transport with Memory Characteristics in an Individual ZnO Nanowire for Realization of a Self-Driven UV Photodetector with Two Symmetrical Electrodes. ACS Appl. Mater. Interfaces 2019, 11, 14932-14943. [CrossRef] 
76. Gupta, A.A.; Arunachalam, S.; Cloutier, S.G.; Izquierdo, R. Fully Aerosol-Jet Printed, High-Performance Nanoporous ZnO Ultraviolet Photodetectors. ACS Photonics 2018, 5, 3923-3929. [CrossRef]

77. Li, L.; Zhang, Y.; Fang, X.; Zhai, T.; Liao, M.; Sun, X.; Koide, Y.; Bando, Y.; Golberg, D. $\mathrm{WO}_{3}$ nanowires on carbon papers: Electronic transport, improved ultraviolet-light photodetectors and excellent field emitters. J. Mater. Chem. 2011, 21, 6525. [CrossRef]

78. Kim, D.; Shin, G.; Yoon, J.; Jang, D.; Lee, S.; Zi, G.; Ha, J.S. High performance stretchable UV sensor arrays of $\mathrm{SnO}_{2}$ nanowires. Nanotechnology 2013, 24, 315502. [CrossRef] [PubMed]

79. Huang, S.; Guo, C.F.; Zhang, X.; Pan, W.; Luo, X.; Zhao, C.; Gong, J.; Li, X.; Ren, Z.F.; Wu, H. Buckled Tin Oxide Nanobelt Webs as Highly Stretchable and Transparent Photosensors. Small 2015, 11, 5712-5718. [CrossRef]

80. Mallick, H.K.; Zhang, Y.; Pradhan, J.; Sahoo MP, K.; Pattanaik, A.K. Influence of particle size and defects on the optical, magnetic and electronic properties of $\mathrm{Al}$ doped $\mathrm{SnO}_{2}$ nanoparticles. J. Alloys Compd. 2021, 854, 156067. [CrossRef]

81. Shahid, M.; Wang, Y.; Yang, J.; Li, T.; Xing, Y.; Cheng, J.; Zhang, M.; Wan, C.; Pan, W. Indium-doped SnO 2 nanobelts for high-performance transparent and flexible photosensors by a facile assembly. Nanotechnology 2017, 28, 335705. [CrossRef]

82. Ogawa, H.; Nishikawa, M.; Abe, A. Hall measurement studies and an electrical conduction model of tin oxide ultrafine particle films. J. Appl. Phys. 1982, 53, 4448-4455. [CrossRef]

83. Mathur, S.; Barth, S.; Shen, H.; Pyun, J.; Werner, U. Size-Dependent Photoconductance in $\mathrm{SnO}_{2}$ Nanowires. Small 2005, 1, $713-717$. [CrossRef] [PubMed]

84. Zhang, X.; Liu, X.; Ning, H.; Yuan, W.; Deng, Y.; Zhang, X.; Wang, S.; Wang, J.; Yao, R.; Peng, J. Characterization studies of the structure and properties of $\mathrm{Zr}$-doped $\mathrm{SnO}_{2}$ thin films by spin-coating technique. Superlattices Microstruct. 2018, 123, 330-337. [CrossRef]

85. Tiwari, N.; Nirmal, A.; Kulkarni, M.R.; John, R.A.; Mathews, N. Enabling high performance n-type metal oxide semiconductors at low temperatures for thin film transistors. Inorg. Chem. Front. 2020, 7, 1822-1844. [CrossRef]

86. Zhang, Y. Electronegativities of elements in valence states and their applications. 1. Electronegativities of elements in valence states. Inorg. Chem. 1982, 21, 3886-3889. [CrossRef]

87. Chetri, P.; Dhar, J.C. Self-powered UV detection using $\mathrm{SnO}_{2}$ nanowire arrays with Au Schottky contact. Mater. Sci. Semicond. Process. 2019, 100, 123-129. [CrossRef]

88. Li, S.; Wang, S.; Liu, K.; Zhang, N.; Zhong, Z.; Long, H.; Fang, G. Self-powered blue-sensitive photodetector based on PEDOT: $\mathrm{PSS} / \mathrm{SnO}_{2}$ microwires organic/inorganic p-n heterojunction. Appl. Phys. A 2015, 119, 1561-1566. [CrossRef]

89. Chen, H.; Hu, L.; Fang, X.; Wu, L. General Fabrication of Monolayer $\mathrm{SnO}_{2}$ Nanonets for High-Performance Ultraviolet Photodetectors. Adv. Funct. Mater. 2012, 22, 1229-1235. [CrossRef]

90. Wu, Y.; Sun, X.; Jia, Y.; Li, D. Review of improved spectral response of ultraviolet photodetectors by surface plasmon. Chin. Phys. $B$ 2018, 27, 126101. [CrossRef]

91. Huang, Y.; Lin, J.; Li, L.; Xu, L.; Wang, W.; Zhang, J.; Xu, X.; Zou, J.; Tang, C. High performance UV light photodetectors based on Sn-nanodot-embedded $\mathrm{SnO}_{2}$ nanobelts. J. Mater. Chem. C 2015, 3, 5253-5258. [CrossRef]

92. Rieu, M.; Camara, M.; Tournier, G.; Viricelle, J.; Pijolat, C.; de Rooij, N.F.; Briand, D. Fully inkjet printed $\mathrm{SnO}_{2}$ gas sensor on plastic substrate. Sens. Actuators B Chem. 2016, 236, 1091-1097. [CrossRef]

93. Devabharathi, N.; Umarji, A.M.; Dasgupta, S. Fully Inkjet-Printed Mesoporous $\mathrm{SnO}_{2}$-Based Ultrasensitive Gas Sensors for Trace Amount $\mathrm{NO}_{2}$ Detection. ACS Appl. Mater. Interfaces 2020, 12, 57207-57217. [CrossRef]

94. Shen, W. Properties of $\mathrm{SnO}_{2}$ based gas-sensing thin films prepared by ink-jet printing. Sens. Actuators B Chem. 2012, 166-167, 110-116. [CrossRef]

95. Huang, S.; Matsubara, K.; Cheng, J.; Li, H.; Pan, W. Highly enhanced ultraviolet photosensitivity and recovery speed in electrospun Ni-doped $\mathrm{SnO}_{2}$ nanobelts. Appl. Phys. Lett. 2013, 103, 141108. [CrossRef]

96. Yuan, W.; Liu, X.; Fang, Z.; Ning, H.; Zhang, X.; Deng, Y.; Deng, P.; Liang, Z.; Yao, R.; Peng, J. The effect of different annealing temperature on transparent conductive $\mathrm{SnO}_{2}$ thin film by solution process. Mol. Cryst. Liq. Cryst. 2018, 676, 44-49. [CrossRef]

97. Park, J.W.; Kang, B.H.; Kim, H.J. A Review of Low-Temperature Solution-Processed Metal Oxide Thin-Film Transistors for Flexible Electronics. Adv. Funct. Mater. 2020, 30, 1904632. [CrossRef] 